\title{
Kajian Penggunaan Alat Berat Pada Proyek Peningkatan Jaringan Irigasi Daerah Irigasi Batang Sangkir-Kerinci
}

\author{
Ayu Athika Dewi*, Azwarman, Ellyta Mona \\ Program Studi Teknik Sipil Universitas Batanghari Jambi \\ *Correspondence email: elfazaathika@gmail.com
}

\begin{abstract}
Abstrak. Alat berat merupakan faktor penting di dalam proyek, terutama proyek-proyek konstruksi dengan skala yang besar. Dalam pekerjaan tanah yang meliputi galian diperlukan alat berat yaitu excavator. Pemilihan alat berat tentunya sangat berpengaruh pada tingkat efisiensi agar dapat menghemat waktu dan biaya. Dalam pengerjaan tugas akhir ini digunakan metode analisis komparatif. Dengan kata lain beberapa jenis dan pabrikan excavator dibandingkan dan diambil keputusan excavator mana yang paling efisien. Maka hasil dari penelitian ini adalah sebagai berikut: 1. Produktivitas excavator : Caterpillar CAT320D=58,14 m³/jam, Komatsu PC200-8MO = 63,52 m³/jam, Komatsu PC130F-7 =39,84m³/jam, dan Hitachi ZX300LC-6 $=73,50 \mathrm{~m}^{3} / \mathrm{jam}$. 2. Excavator yang efisien digunakan yaitu Komatsu PC200-8 dengan waktu 94,40 jam, biaya per jam Rp. 628.869,77 dan biaya total Rp. 59.365.306,71. Dengan selisih waktu lebih cepat 8,7 jam dari Caterpillar CAT320D dan dapat menghemat pengeluaran sebesar Rp. 6.695.416,67.
\end{abstract}

Kata Kunci: alat berat, excavator, konstruksi, efisien

\section{PENDAHULUAN}

Saat ini, alat berat merupakan faktor penting di dalam proyek, terutama proyek-proyek konstruksi dengan skala yang besar. Tujuan penggunaan alat berat tersebut untuk memudahkan manusia dalam mengerjakan pekerjaannya sehingga hasil yang diharapkan dapat tercapai dengan lebih mudah pada waktu yang relatif lebih singkat. (Ahmad Kholil, 2012:1)

Alat berat adalah alat bantu konstruksi dengan mesin berukuran besar untuk memudahkan dalam pelaksaan pekerjaan berat dilapangan seperti pekerjaan tanah dan memindahkan bahan/material bangunan.

\section{Waktu Siklus Excavator (Cycle Time)}

Untuk cycle time terdiri dari empat gerakan dasar yaitu : (Djoko Wilopo, 2011:46)

1. Waktu menggali (digging time)

2. Waktu mengayun (swing loaded)

3. Membongkar beban (dumping)

4. Mengayun balik (swing empty)

\section{Produktivitas}

Produktivitas adalah hasil dari proses produksi dalam satuan waktu tertentu. Contoh: $\mathrm{m} / \mathrm{jam}$, ton/jam, $\mathrm{m}^{2} / \mathrm{jam}$, dan lain-lain. Menurut Albar (Dalam Standar Parameter Penambangan PT. PAMA, 2015)

$$
\text { Produktivitas }=\text { kapasitas alat } \mathrm{x} \text { efesiensi kerja alat } \mathrm{x} \frac{60}{\text { waktu siklus }}
$$

\section{Perhitungan Produktivitas Excavator}

Rumus umum perhitungan produktivitas excavator:

1. Produksi Persiklus

$$
\begin{array}{ll}
\text { 1. Produksi Persiklus } & \mathrm{q}=\mathrm{q} 1 \times \mathrm{k}=\mathrm{m}^{3} \\
\text { 2. Produksi Perjam } & \mathrm{Q}=\underline{\mathrm{q} \times 3600 \times E}=\mathrm{m}^{3} / \mathrm{jam}
\end{array}
$$

Keterengan:

$\mathrm{Q}=$ Kapasitas produksi $\left(\mathrm{m}^{3} / \mathrm{jam}\right)$

$\mathrm{q} 1=$ Kapasitas bucket $\left(\mathrm{m}^{3}\right)$

$\mathrm{k}=$ Bucket fill factor

$\mathrm{E} \quad=$ Faktor efisiensi

$\mathrm{CT}=$ Waktu siklus/ cycle time (menit)

Tabel. 1 Bucket Fill Factor

\begin{tabular}{lc}
\hline \multicolumn{1}{c}{ Material } & BFF/k (\%) \\
\hline Tanah dan tanah organic & $80-100$ \\
Pasir dan kerikil & $90-100$ \\
\hline
\end{tabular}


Ayu Athika Dewi, Azwarman dan Ellyta Mona, Kajian Penggunaan Alat Berat Pada Proyek Peningkatan Jaringan Irigasi Daerah Irigasi Batang Sangkir-Kerinci

\begin{tabular}{ll}
\hline Lempung keras & $65-95$ \\
Lempung basah & $50-90$ \\
Batuan dengan peledakan buruk & $40-70$ \\
Batuan dengan peledakan baik & $70-90$ \\
\hline
\end{tabular}

Sumber: Construction Methods and Management, 1998

3. Waktu Siklus (Cycle Time)

Rumus perhitungan cycle time adalah sebagai berikut :

$\mathrm{CT}=$ waktu gali (t1) + waktu putar (t2) x 2 + waktu buang (t3)

Keterangan:

CT

Waktu gali (t1)

Waktu putar (t2)

Waktu buang (t3)

$=$ Cycle time (detik)

= berdasarkan kedalaman galian (detik)

= berdasarkan sudut dan kecepatan putar (detik)

$=$ berdasarkan kondisi pembuangan material (detik)

a. Pembuangan kedalam dumptruck $=4-7$ detik

b. Ketempat pembuangan $=3-6$ detik

Tabel 2. Waktu Gali

\begin{tabular}{ccccc}
\hline $\begin{array}{c}\text { Kondisi Gali/ } \\
\text { Kedalaman Gali }\end{array}$ & $\begin{array}{c}\text { Ringan } \\
\text { (detik) }\end{array}$ & $\begin{array}{c}\text { Sedang } \\
\text { (detik) }\end{array}$ & $\begin{array}{c}\text { Agak Sulit } \\
\text { (detik) }\end{array}$ & $\begin{array}{c}\text { Sulit } \\
\text { (detik) }\end{array}$ \\
\hline $0-2 \mathrm{~m}$ & 6 & 9 & 15 & 26 \\
$2-4 \mathrm{~m}$ & 7 & 11 & 17 & 28 \\
$4-$ lebih & 8 & 13 & 19 & 30 \\
\hline
\end{tabular}

Sumber: Rochmanhadi, 1985

Tabel. 3 Waktu Putar

\begin{tabular}{cc}
\hline Sudut Putar & Waktu Putar \\
\hline $45-90$ (derajat) & $4-7$ \\
$90-180$ (derajat) & $5-8$ \\
\hline
\end{tabular}

Sumber: Rochmanhadi, 1985

Nilai real cycle time didapat dari kondisi yang disesuaikan saat menggali dan membongkar beban dengan rumus sebagai berikut:

$\mathrm{CT}=\mathrm{Std}$ CT $\mathrm{x} \mathrm{Fk}$

Keterangan:

$\mathrm{CT} \quad=$ Cycle time (detik)

Std CT $=$ Standart cycle time $($ detik $)$

$\mathrm{Fk} \quad=$ Faktor Konversi

Tabel. 4 Faktor Konversi Untuk Kedalaman dan Sudut Putar

\begin{tabular}{ccccccc}
\hline $\begin{array}{c}\text { Kedalaman Penggalian } \\
\text { (\% dari maks) }\end{array}$ & $\mathbf{4 5}$ & $\mathbf{6 0}$ & $\mathbf{7 5}$ & $\mathbf{9 0}$ & $\mathbf{1 2 0}$ & $\mathbf{1 8 0}$ \\
\hline $\mathbf{3 0}$ & 1,33 & 1,26 & 1,21 & 1,15 & 1,08 & 0,95 \\
$\mathbf{5 0}$ & 1,28 & 1,21 & 1,16 & 1,10 & 1,03 & 0,91 \\
$\mathbf{7 0}$ & 1,16 & 1,10 & 1,05 & 1,00 & 0,94 & 0,83 \\
$\mathbf{9 0}$ & 1,04 & 1,00 & 0,95 & 0,90 & 0,86 & 0,75 \\
\hline
\end{tabular}

Sumber: Construction Methods and Management, 1998

\section{Efesiensi Kerja (E)}

Untuk mendapatkan gambaran produksi yang sebenarnya digunakan faktor koreksi dari efisiensi kerja alat berat yang disesuaikan dengan hasil produksi alat yang sebenarnya. 
Ayu Athika Dewi, Azwarman dan Ellyta Mona, Kajian Penggunaan Alat Berat Pada Proyek Peningkatan Jaringan Irigasi Daerah Irigasi Batang Sangkir-Kerinci

Tabel. 5 Efisiensi Kerja

\begin{tabular}{lc}
\hline Kondisi Operasi Alat & Efisiensi Kerja \\
\hline Baik Sekali & 0,83 \\
Baik & 0,75 \\
Sedang & 0,67 \\
Buruk & 0,58 \\
\hline
\end{tabular}

Sumber: Albar Cipta Cahya, 2015

\section{METODE}

Tugas akhir ini dikerjakan dengan cara membandingkan empat tipe alat berat excavator atau umumnya disebut metode analisis komparatif yang kemudian dari hasil pembahasan diambil keputusan excavator mana yang paling efisien dari segi waktu dan biaya.

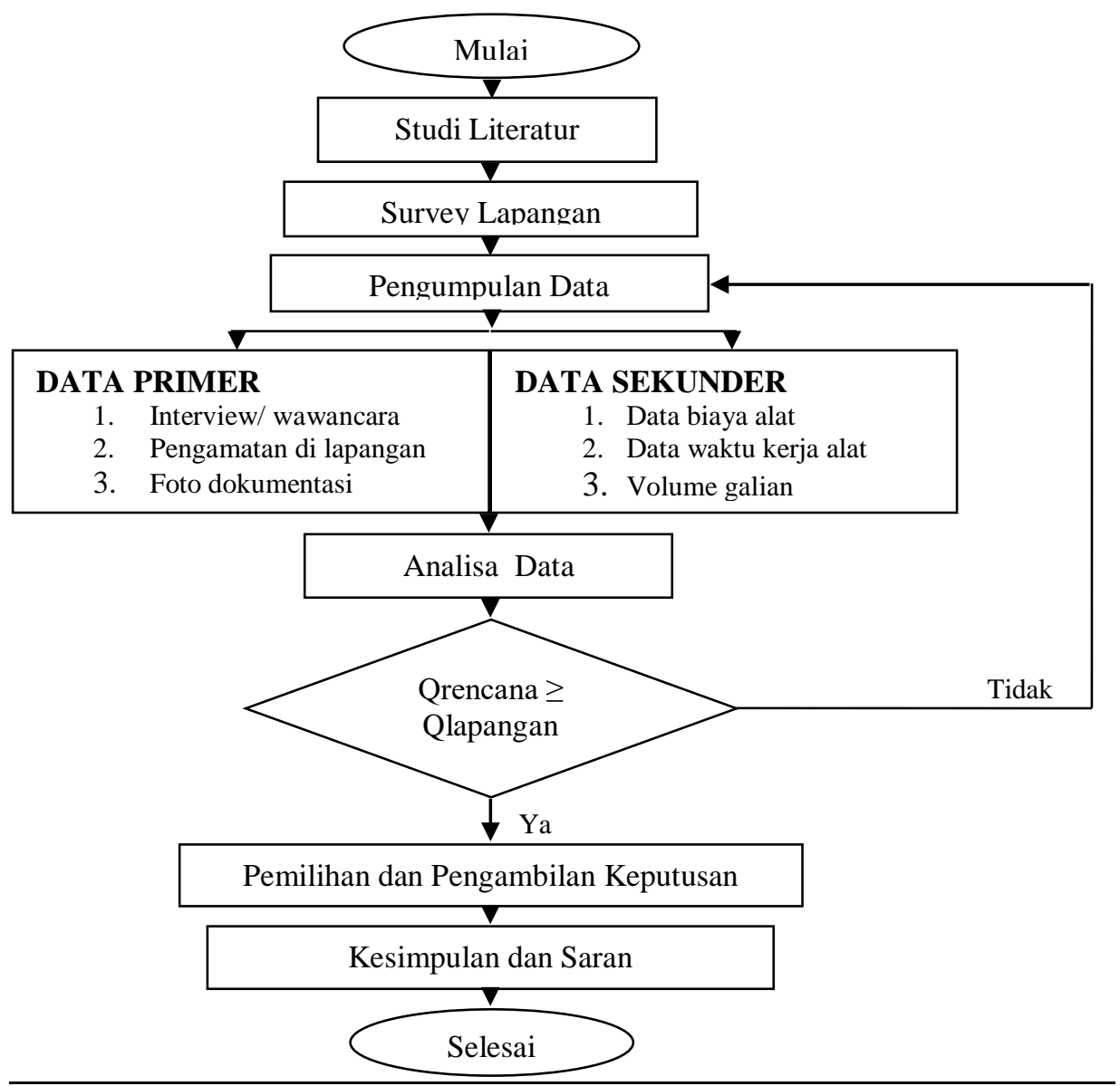

Gambar. 1 Bagan Alir (flowchart) Penelitian

\section{HASIL DAN PEMBAHASAN}

\section{a. Analisa Waktu}

Membandingan produktivitas keempat tipe excavator dilakukan dengan membuat simulasi perhitungan, dimana ada dua variabel yang perlu disamakan yaitu :

1. Faktor konversi menggunakan sudut putar $=90^{\circ}$

2. Efesiensi kerja $=0,83$

\section{Perhitungan Produktivitas Excavator}

A. Caterpillar CAT320D

$\mathrm{q}=\mathrm{q} 1 \times \mathrm{k}=\mathrm{m}^{3}$

$\mathrm{q}=0,90 \times 0,8=0,72 \mathrm{~m}^{3}$

$\mathrm{CT}=\mathrm{t} 1+\mathrm{t} 2+\mathrm{t} 3+\mathrm{t} 4$

$\mathrm{CT}=15+6+5+6=32$ detik

$\mathrm{CT}=\mathrm{Std} \mathrm{CT} \times \mathrm{Fk}$

Kondisi penggalian $=\quad$ kedalaman penggalian $\quad \mathrm{x} 100 \%$ 
Ayu Athika Dewi, Azwarman dan Ellyta Mona, Kajian Penggunaan Alat Berat Pada Proyek Peningkatan Jaringan Irigasi Daerah Irigasi Batang Sangkir-Kerinci

Kondisi penggalian $=\frac{1,7}{9,89} \times 100 \%=17 \%$

$\mathrm{Fk}=$ kedalaman penggalian dan sudut putar $90^{\circ}$ didapat 1,15 dari tabel.4

$\mathrm{CT}=32 \times 1,15=36,80 \approx 37$ detik

$\mathrm{Q}=\frac{\mathrm{q} \times 3600 \times \mathrm{E}}{\mathrm{CT}}=\frac{0,72 \times 3600 \times 0,83}{37}=58,14 \mathrm{~m}^{3} / \mathrm{jam}$

B. Komatsu PC 200-8

$\mathrm{q}=\mathrm{q} 1 \times \mathrm{k}=\mathrm{m}^{3}$

$\mathrm{q}=0,93 \times 0,8=0,74 \mathrm{~m}^{3}$

$\mathrm{CT}=\mathrm{t} 1+\mathrm{t} 2+\mathrm{t} 3+\mathrm{t} 4$

$\mathrm{CT}=15+5+5+5=30$ detik

$\mathrm{CT}=\mathrm{Std} \mathrm{CT} \times \mathrm{Fk}$

Kondisi penggalian $=\quad$ kedalaman penggalian

$\mathrm{x} 100 \%$

Kondisi penggalian $=\frac{1,7}{9,70} \times 100 \%=18 \%$

$\mathrm{Fk}=$ kedalaman penggalian dan sudut putar $90^{\circ}$ didapat 1,15 dari tabel.4

$\mathrm{CT}=30 \times 1,15=34,50 \approx 35$ detik

$\mathrm{Q}=\frac{\mathrm{q} \times 3600 \times \mathrm{E}}{\mathrm{CT}}=\frac{0,74 \times 3600 \times 0,83}{35}=63,52 \mathrm{~m}^{3} / \mathrm{jam}$

C. Komatsu PC130F-7

$\mathrm{q}=\mathrm{q} 1 \times \mathrm{k}=\mathrm{m}^{3}$

$\mathrm{q}=0,55 \times 0,8=0,44 \mathrm{~m}^{3}$

$\mathrm{CT}=\mathrm{t} 1+\mathrm{t} 2+\mathrm{t} 3+\mathrm{t} 4$

$\mathrm{CT}=15+5+4+5=29$ detik

$\mathrm{CT}=\mathrm{Std} \mathrm{CT} \times \mathrm{Fk}$

Kondisi penggalian $=\quad$ kedalaman penggalian $\quad \times 100 \%$

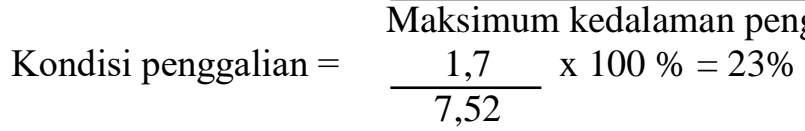

$\mathrm{Fk}=$ kedalaman penggalian dan sudut putar $90^{\circ}$ didapat 1,15 dari tabel.4

$\mathrm{CT}=29 \times 1,15=33,35 \approx 33$ detik

$\mathrm{Q}=\frac{\mathrm{q} \times 3600 \times \mathrm{E}}{\mathrm{CT}}=\frac{0,44 \times 3600 \times 0,83}{33}=39,84 \mathrm{~m}^{3} / \mathrm{jam}$

D. Hitachi ZX 300LC-6

$\mathrm{q}=\mathrm{q} 1 \mathrm{x} \mathrm{k}=\mathrm{m}^{3}$

$\mathrm{q}=1,23 \times 0,8=0,98 \mathrm{~m}^{3}$

$\mathrm{CT}=\mathrm{t} 1+\mathrm{t} 2+\mathrm{t} 3+\mathrm{t} 4$

$\mathrm{CT}=15+6+7+6=34$ detik

$\mathrm{CT}=\mathrm{Std} \mathrm{CT} \times \mathrm{Fk}$

Kondisi penggalian $=$

kedalaman penggalian

x $100 \%$

Kondisi penggalian $=\frac{1,7}{10,52} \times 100 \%=16 \%$

$\mathrm{Fk}=$ kedalaman penggalian dan sudut putar $90^{\circ}$ didapat 1,15 dari tabel 4

$\mathrm{CT}=34 \times 1,15=39,10 \approx 40$ detik

$\mathrm{Q}=\frac{\mathrm{q} \times 3600 \times \mathrm{E}}{\mathrm{CT}}=\frac{0,98 \times 3600 \times 0,83}{40}=73,50 \mathrm{~m}^{3} / \mathrm{jam}$

\section{Perhitungan Kebutuhan Alat}

Contoh perhitungan diambil Caterpillar CAT320D, untuk Komatsu PC200-8MO, Komatsu PC130F-7, dan Hitachi ZX300LC-6 cara perhitungannya sama. 
Ayu Athika Dewi, Azwarman dan Ellyta Mona, Kajian Penggunaan Alat Berat Pada Proyek Peningkatan Jaringan Irigasi Daerah Irigasi Batang Sangkir-Kerinci

1. Jam Kerja yang dibutuhkan

$=\frac{\text { Volume galian }}{\text { Produksi perjam }}=\frac{5.996}{58,14}=103,13 \mathrm{jam}$

2. Waktu Kerja

$=77$ hari $\mathrm{x} 7 \mathrm{jam}=539$ jam kerja

Jadi, excavator yang dibutuhkan adalah

$=\frac{\text { jam kerja yang dibutuhkan }}{\text { jam kerjatersedia }}$

$=\frac{103,13}{539}=0,19 \approx 1$ Unit

Tabel. 6 Produktivitas Excavator

\begin{tabular}{|c|c|c|c|c|c|c|}
\hline URAIAN & KODE & $\begin{array}{l}\text { Caterpillar } \\
\text { CAT 320D }\end{array}$ & $\begin{array}{l}\text { Komatsu } \\
\text { PC 200-8 }\end{array}$ & $\begin{array}{l}\text { Komatsu } \\
\text { PC 130F-7 }\end{array}$ & $\begin{array}{c}\text { Hitachi } \\
\text { ZX 300LC-6 }\end{array}$ & SATUAN \\
\hline Kapasitas bucket & $\mathrm{q} 1$ & 0,90 & 0,93 & 0,55 & 1,23 & $\mathrm{~m}^{3}$ \\
\hline Kedalaman penggalian & & 1,7 & 1,7 & 1,7 & 1,7 & M \\
\hline Volume Galian & V & 5.996 & 5.996 & 5.996 & 5.996 & $\mathrm{~m}^{3}$ \\
\hline Maks. Kedalaman penggalian & & 9,89 & 9,70 & 7,52 & 10,52 & M \\
\hline $\begin{array}{l}\text { Bucket Fill Factor } \\
\text { dari Tabel. } 1\end{array}$ & $\mathrm{~K}$ & 0,80 & 0,80 & 0,80 & 0,80 & \\
\hline Persentase kedalaman & & 17 & 18 & 23 & 16 & $\%$ \\
\hline $\begin{array}{l}\text { Faktor Efisiensi Kerja } \\
\text { dari tabel } 5\end{array}$ & $\mathrm{E}$ & 0,83 & 0,83 & 0,83 & 0,83 & \\
\hline Cycle Time & CT & & & & & Detik \\
\hline Waktu gali & $\mathrm{t} 1$ & 15 & 15 & 15 & 15 & Detik \\
\hline Waktu putar & $\mathrm{t} 2$ & 6 & 5 & 5 & 6 & Detik \\
\hline Waktu buang & $\mathrm{t} 3$ & 5 & 5 & 4 & 7 & Detik \\
\hline Waktu putar kosong & $\mathrm{t} 4$ & 6 & 5 & 5 & 6 & Detik \\
\hline$\Sigma \mathrm{t}$ & $\mathrm{CT}$ & 32 & 30 & 29 & 34 & Detik \\
\hline StdCT $\times$ Fk & & 37 & 35 & 33 & 40 & Detik \\
\hline$q=q 1 \times k$ & Q & 0,72 & 0,74 & 0,44 & 0,98 & $\mathrm{~m}^{3}$ \\
\hline Produktivitas & $\mathrm{Q}$ & 58,14 & 63,52 & 39,84 & 73,50 & $\mathrm{~m}^{3} / \mathrm{jam}$ \\
\hline Kebutuhan Excavator & & 1 & 1 & 1 & 1 & Unit \\
\hline
\end{tabular}

Sumber: Analisa Data, 2019

\section{b. Analisa Biaya}

Membandingkan keempat tipe excavator untuk perhitungan analisa biaya juga dilakukan dengan membuat simulasi perhitungan, dimana beberapa variabel disamakan yaitu :

1. Umur ekonomis $=5$ tahun

2. Jam kerja alat dalam satu tahun $=2000$ jam

3. Nilai sisa $\quad=10 \%$ dari harga beli

4. Rate asuransi $=2 \%$

5. Tingkat suku bunga $\quad=10 \%$ pertahun

6. Upah operator = Rp. 105.000/ $7 \mathrm{jam}$

7. Upah pembantu operator $\quad=\mathrm{Rp} .84 .000 / 7 \mathrm{jam}$

8. Bahan bakar solar industry (Ms) = Rp. 8.200/ liter

9. Minyak pelumas (Mp) = Rp. $45.000 /$ liter

Contoh perhitungan diambil Caterpillar CAT320D, untuk Komatsu PC200-8MO, Komatsu PC130F-7, dan Hitachi ZX300LC-6 cara perhitungannya sama.

Perhitungan Biaya Operasional
A. Uraian Peralatan
1. Jenis Peralatan
$=$ EXCAVATOR Caterpillar CAT320D
2. Tenaga $(\mathrm{Pw})$
3. Umur Ekonomis Alat (A)
$=138 \mathrm{Hp}$
$=5$ Tahun
4. Jam Kerja Dalam Satu Tahun
$=2000 \mathrm{Jam}$ 
Ayu Athika Dewi, Azwarman dan Ellyta Mona, Kajian Penggunaan Alat Berat Pada Proyek Peningkatan Jaringan Irigasi Daerah Irigasi Batang Sangkir-Kerinci

5. Harga Alat (B)

$$
=\text { Rp. } 883.000 .000
$$

6. Harga Penyusutan $=$ Rp. 794.700 .000

B. Biaya Kerja Alat Perjam

1. Nilai sisa alat $(\mathrm{C})$

$=10 \% \times \mathrm{B}$

$=10 \% \times 883.000 .000$

$=$ Rp. 88.300 .000

2. Harga penyusutan

$=\mathrm{B}-\mathrm{C}$

$=883.000 .000-88.300 .000=794.700 .000$

3. Biaya Penyusutan

$=\frac{\text { Harga penyusutan }}{\mathrm{A} \times \mathrm{W}}$

$=\frac{794.700 .000}{5 \times 2000}=$ Rp. 79.470

4. Faktor pengembalian modal (D)

$=\frac{18 \% \times\left[(1+18 \%)^{\wedge} 5\right]}{\left[(1+18 \%)^{5}\right]-1}$

$=0,32$

5. Biaya pengembalian modal $(\mathrm{E})$

$=\frac{(\mathrm{B}-\mathrm{C}) \times \mathrm{D}}{\mathrm{W}}$

$=\frac{(883.000 .000-88.300 .000) \times 0,32}{2000}$

$=$ Rp. 127.063,73

6. Asuransi (F)

$=\frac{0,002 \times \mathrm{B}}{\mathrm{W}}$

$=\frac{0,002 \times 883.000 \cdot 000}{2000}=$ Rp. 88,30

C. Biaya Operasi Perjam Kerja

1. Bahan bakar $(\mathrm{H})$

$=12 \% \times \mathrm{Pw} \times \mathrm{Ms}$

$=12 \% \times 138 \times 8.200=$ Rp. 135.792

2. Pelumas (I)

$=2,5 \% \times \mathrm{Pw} \times \mathrm{Mp}$

$=2,5 \% \times 138 \times 45.000=$ Rp. 155.250

3. Biaya bengkel $(\mathrm{J})$

$=\frac{8,75 \% \times \mathrm{B}}{\mathrm{W}}$

$=\frac{8,75 \% \times 883.000 .000}{2000}$

$=$ Rp. $38.631,25$

4. Biaya Perawatan dan Perbaikan (K)

$=\frac{17,5 \% \times \mathrm{B}}{\mathrm{W}}$

$=\frac{17,5 \% \times 883.000 .000}{2000}=$ Rp. $77.262,50$

5. Operator (L)

$=\frac{1 \text { orang }}{7 \text { jam }}=\frac{105.000}{7 \text { jam }}=15.000 / \mathrm{jam}$

6. Pembantu operator (M) 
Ayu Athika Dewi, Azwarman dan Ellyta Mona, Kajian Penggunaan Alat Berat Pada Proyek Peningkatan Jaringan Irigasi Daerah Irigasi Batang Sangkir-Kerinci

$$
=\frac{1 \text { orang }}{7 \text { jam }}=\frac{84.000}{7 \text { jam }}=12.000 / \mathrm{jam}
$$

D. Total Biaya Operasi Alat Perjam

1. Biaya Penyusutan = Rp. 79.470

2. Biaya Operasi = Rp. 318.042

3. Biaya Perbaikan = Rp. $77.262,50$

4. Biaya Bengkel = Rp. $38.631,25$

5. Bunga Modal = Rp. $127.063,73$

6. Asuransi = Rp. 88,30

Total Biaya Alat Perjam $\quad=$ Rp. 640.557,78

\section{Hasil Analisa}

Tabel. 7 Rekapitulasi Waktu dan Biaya Excavator

\begin{tabular}{lcccrrr}
\hline Jenis Excavator & $\begin{array}{c}\text { Produktivitas } \\
\left(\mathbf{m}^{3 / j a m}\right)\end{array}$ & $\begin{array}{c}\text { Waktu } \\
(\mathbf{J a m})\end{array}$ & \multicolumn{1}{c}{ Perjam } & \multicolumn{1}{c}{ Total } \\
\hline Caterpillar CAT 320D & 58,14 & 103,13 & $\mathrm{Rp}$ & $640.557,78$ & $\mathrm{Rp}$ & $66.060 .723,38$ \\
Komatsu PC200-8MO & 63,52 & 94,40 & $\mathrm{Rp}$ & $628.869,77$ & $\mathrm{Rp}$ & $59.365 .306,71$ \\
Komatsu PC130F-7 & 39,84 & 150,50 & $\mathrm{Rp}$ & $444.525,77$ & $\mathrm{Rp}$ & $66.901 .128,13$ \\
Hitachi ZX300LC-6 & 73,50 & 81,57 & $\mathrm{Rp}$ & $1.720 .210,59$ & $\mathrm{Rp} \mathrm{140.317.578,00}$ \\
\hline
\end{tabular}

Sumber: Analisa Data, 2019

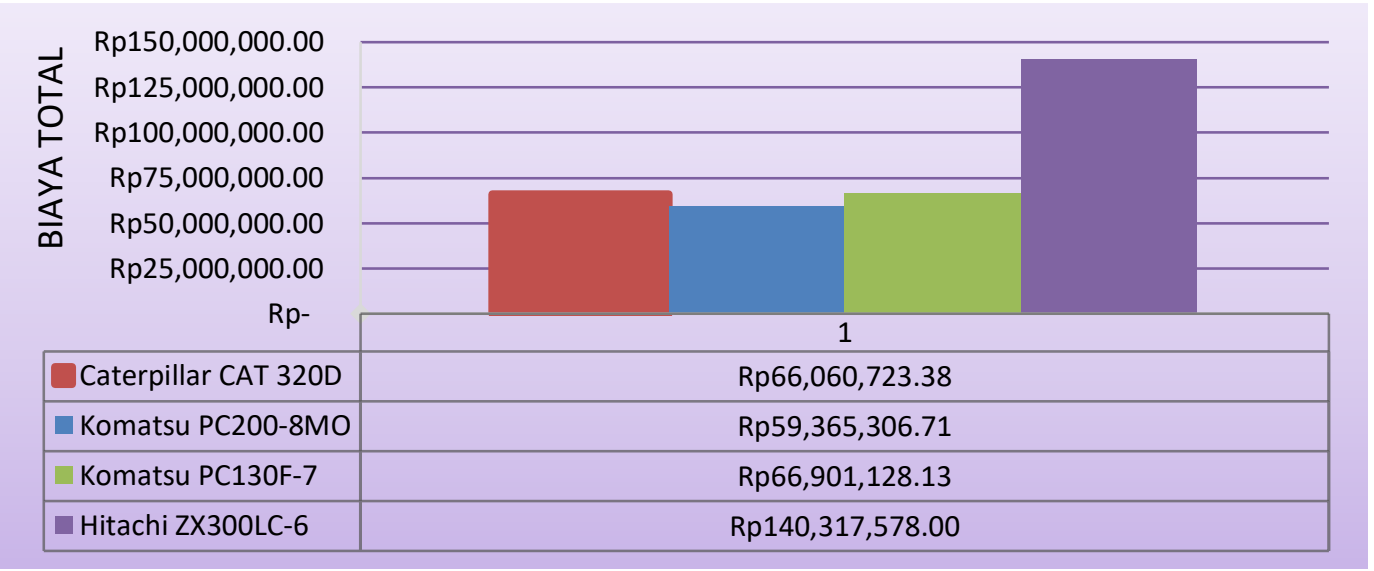

Gambar. 2 Grafik Biaya Total Excavator

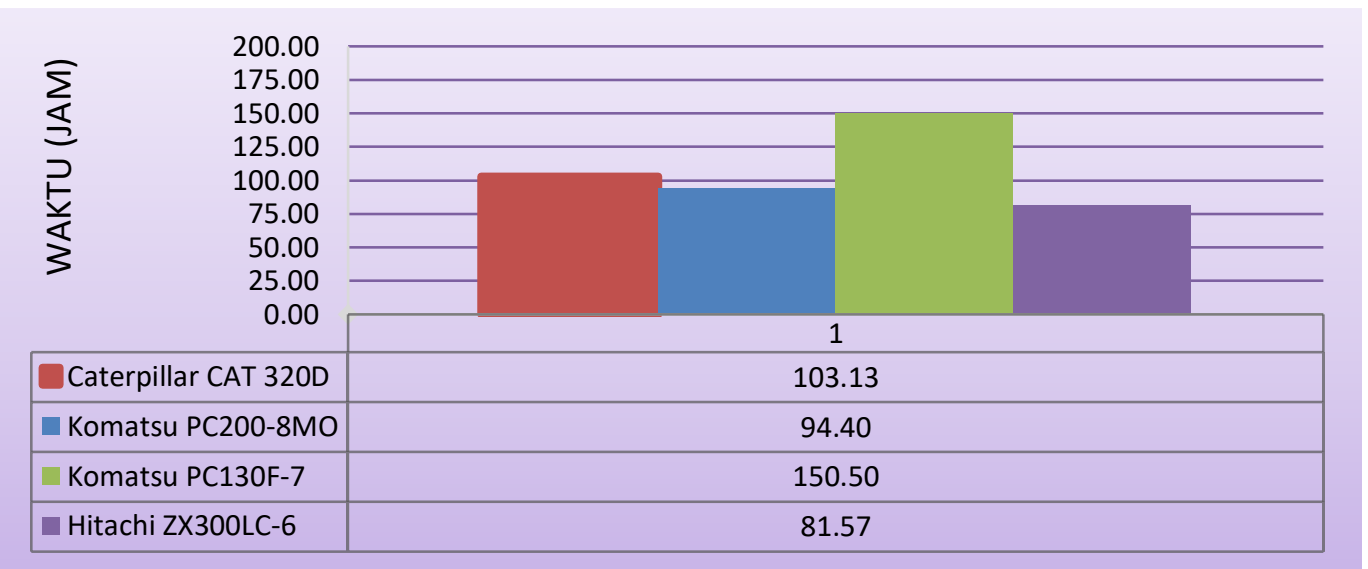

Gambar. 3 Grafik Waktu Excavator

\section{SIMPULAN}

Berdasarkan dari hasil perhitungan dan pembahasan, maka sebagai kesimpulan dari penelitian ini adalah sebagai berikut:

1. Dari hasil perhitungan produktivitas excavator untuk keempat type adalah sebagai berikut:

a. Caterpillar CAT320D $=58,14 \mathrm{~m}^{3} / \mathrm{jam}$ 
Ayu Athika Dewi, Azwarman dan Ellyta Mona, Kajian Penggunaan Alat Berat Pada Proyek Peningkatan Jaringan Irigasi Daerah Irigasi Batang Sangkir-Kerinci
b. Komatsu PC200-8MO = 63,52 $\mathrm{m}^{3} / \mathrm{jam}$
c. Komatsu PC130F-7 = $39,84 \mathrm{~m}^{3} / \mathrm{jam}$
d. Hitachi ZX300LC-6 =73,50 $\mathrm{m}^{3} / \mathrm{jam}$

2. Dari hasil perhitungan excavator yang efisien digunakan yaitu Komatsu PC200-8MO dengan selisih sebagai berikut:

Tabel. 8 Selisih Waktu dan Biaya Excavator

\begin{tabular}{rcccc}
\hline Jenis Excavator & $\begin{array}{c}\text { Waktu } \\
(\text { Jam) }\end{array}$ & Biaya Total & Selisih Waktu (Jam) & Selisih Biaya (Rp) \\
\hline Caterpillar CAT 320D & 103,13 & Rp 66.060.723,38 & & \\
Komatsu PC200-8MO & 94,40 & Rp 59.365.306,71 & 8,73 & Rp $6.695 .416,67$ \\
\hline
\end{tabular}

Sumber: Analisa Data, 2019

\section{DAFTAR PUSTAKA}

BPS. (2013). Kerinci Dalam Angka 2013. Kerinci: BPS Kabupaten Kerinci.

Dennis. (2018, Februari 5). Alat Berat. Retrieved from Wikipedia: https://id.m.wikipedia.org/w/Alat_berat

Kholil, A. (2012). Alat Berat. Bandung: PT Remaja Rosda Karya.

Kirmanto, D. (2014). Katalog Alat Berat Konstruksi 2013. Jakarta: Pusat Pembinaan Sumber Daya Investasi Badan Pembinaan Konstruksi Kementrian PU.

Rajasa, A. C. (2015). Analisa Penggunaan Alat Berat Berasarkan Pada Efisiensi Pekerjaan Galian Pembangunan Jember Icon. Jember: Universitas Jember.

Rochmanhadi. (1992). Alat-alat Berat dan Penggunaannya. Jakarta: Badan Penerbit Pekerjaan Umum.

Rostiyanti, S. F. (2008). Alat Berat Untuk Proyek Konstruksi. Jakarta: PT Rineka Cipta.

Silvano, V. G. (2015). Makalah Alat Berat dan Pemidahan Tanah Mekanis. Jakarta: Politeknik Negeri Jakarta.

Tenriajeng, A. T. (2003). Pemindahan Tanah Mekanis. Jakarta: Gunadarma.

Wilopo, D. (2009). Metode Konstruksi dan Alat-alat Berat. Jakarta: Universitas Indonesia. 